
$\mathbf{R}$
$\mathbf{0}$
$\mathbf{Z}$
$\mathbf{P}$
$\mathbf{R}$
A
W
Kwartalnik Historyczny Rocznik CXXVIII, 2021, 1
PL ISSN 0023-5903

\author{
ANDRII PORTNOV \\ https://orcid.org/0000-0003-1913-8811 \\ Europejski Uniwersytet Viadrina, Frankfurt nad Odrą
}

\title{
KILKA REFLEKSJI O UKRAIŃSKIEJ (I NIE TYLKO) HISTORIOGRAFII POSTSOWIECKIEJ
}

\begin{abstract}
Abstrakt: Celem artykułu jest podsumowanie głównych tendencji w rozwoju postsowieckiej historiografii ukraińskiej i umieszczenie ich w szerszym kontekście współczesnych wyzwań stojących przed naukami humanistycznymi, w tym rosnącego wpływu „polityki tożsamości”. Autor opowiada się za istotnością kontekstualnej analizy debat historiograficznych oraz wspiera zasadnicze znaczenie zachowania akademickiej wolności i otwartej debaty.
\end{abstract}

Słowa kluczowe: historiografia ukraińska, syntezy historyczne, polityka tożsamości, kultura dyskusji.
Abstract: The article aims to summarise the main trends in the development of post-Soviet Ukrainian historiography and to place them within the broader context of contemporary challenges facing the Humanities, including the growing impact of "identity politics". The author argues for the significance of contextualizing analysis of historiographical debates and supports the crucial importance of preserving academic freedom and open discussion.

Keywords: Ukrainian historiography, historical syntheses, identity politics, culture of discussion.

W 1938 r. Raymond Aron, jeden z największych francuskich myślicieli XX w., „samotny intelektualista”, który nie ulegał przelotnym modom, obronił rozprawę doktorską na temat „granic obiektywizmu historiografii"1. Dowodził w niej, że analizy historycznej nie sposób oddzielić od osobowości badacza. A świadomość uczestniczenia w procesie opisywania i zgłębiania tematujednocześnie „wzbogacaiogranicza” interpretacje autora.

${ }^{1}$ R. Aron, Introduction à la philosophie de l'histoire. Essai sur les limites de l'objectivité historique, Paris 1986. 
W drugiej połowie lat dziewięćdziesiątych studiowałem na Wydziale Historii Uniwersytetu Dniepropietrowskiego (obecnie Dnieprzańskiego). Był to na Ukrainie przełomowy czas dla historii jako dziedziny nauki. W programie nauczania nie było już „naukowego komunizmu”, a niedawni wykładowcy historii Partii przekwalifikowywali się na politologów. Zaczęły się wówczas pojawiać - choć jeszcze bardzo ograniczone możliwości wyjazdów na zagraniczne staże i stypendia. Jednocześnie sytuacja gospodarcza w kraju i warunki na państwowych uniwersytetach zdecydowanie nie należały do najlepszych. $W$ drugiej połowie lat dziewięćdziesiątych wciąż odczuwalny był wpływ transformacji: otwarcie granic po upadku ZSRR i pojawienie się pierwszych tłumaczeń „zachodnich" tekstów naukowych na język ukraiński ${ }^{2}$. Do wyżej wymienionych zjawisk należy również dodać upowszechnienie dorobku historiografii ukraińskiej diaspory. Największy wpływ miały na mnie w pierwszych latach studiów prace kanadyjskiego historyka Iwana Łysiaka-Rudnickiego, opublikowane w Kijowie w 1994 r. ${ }^{3}$

Trzeba podkreślić, że ukraińska historiografia sowiecka nie dorównywała poziomowi polskiej. Wiązało się to przede wszystkim z ograniczonym dostępem do publikacji w językach obcych (zaważyło tu obowiązkowe „pośrednictwo” i ścisła kontrola Moskwy), jak i brakiem „nieoficjalnego życia intelektualnego" (także naukowego). W czasach sowieckich na Ukrainie nie rozwinął się w takim stopniu jak w Polsce tzw. drugi obieg. W latach dziewięćdziesiątych na rynku wydawniczym pojawiło się wiele nowych czasopism intelektualnych, jak np. „Heneza”, „Duch i Litera”, „Krytyka”, „Ukraina Moderna”, „Ukrainskyj humanitarnyj ohliad”. Większość z nich z powodu problemów finansowych lub braku zainteresowania ze strony potencjalnych autorów przestała się ukazywać w pierwszej dekadzie XXI w. Jednocześnie postępował proces utraty prestiżu zawodu historyka.

Jeśli chodzi o rozwój samej historiografii, można wymienić dwa dominujące kierunki - nacjonalizację i internacjonalizację. Pierwszy opierał się na idei „powrotu do tradycji narodowych”, a jego celem było „wypełnienia białych plam” w sowieckiej narracji o przeszłości. Natomiast internacjonalizacja wiązała się ze zbliżeniem z zachodnią humanistyką. Było to poważne wyzwanie dla wielu ukraińskich uczonych. „Zachodnie" priorytety metodologiczne nie koncentrowały się bowiem na historii narodowej.

${ }^{2}$ Przypomnę, że w czasach sowieckich zagraniczna literatura naukowa na Ukrainie była dostępna tylko w języku rosyjskim. Nawet Marksa na ukraiński tłumaczono z rosyjskiego, a nie z niemieckiego oryginału.

${ }^{3}$ I. Lysâk-Rudnyc'kyj, Istoryčnì ese, t. 1-2, Kyïv 1994. 
Patrząc z perspektywy czasu na rozwój ukraińskiej historiografii po rozpadzie ZSRR, można powiedzieć, że ogólnie była zgodna ze schematem opisanym przez Ivana Krasteva i Stephena Holmesa. Sprowadzała się do pragnienia postsowieckiego społeczeństwa, aby przyjmować wartości, zachowania i podejście akceptowane na Zachodzie ${ }^{4}$. Nowe pojęcia i koncepcje zdominowały retorykę ukraińskiej nauki postsowieckiej. Najpierw była to „mentalność” (z tekstami szkoły Annales) i „cywilizacja” (tłumaczenia Arnolda Toynbeego i Oswalda Spenglera). Trochę później (już na początku XXI w.) pojawiły się „wyobrażone wspólnoty” Benedicta Andersona i „orientalizm” Edwarda Saida. Następnie, pod wpływem prac Maurice'a Halbwachsa, Pierre'a Nory i Aleidy Assmann, pojawiły się rozważania na temat „pamięci historycznych”. Dominacja wspomnianych „zachodnich" koncepcji w latach dziewięćdziesiątych była absolutna. Najlepiej widziane było uważne „studiowanie dorobku zachodniej nauki”, naśladowanie jej lub przynajmniej ozdabianie własnych tekstów „nowoczesnymi pojęciami”. Wydaje się, że strategie udomowienia „zachodnich" koncepcji sprowadzały się głównie do zmiany samego języka bez głębszej refleksji na temat kontekstu zapożyczonych kategorii i były przez wielu naiwnie utożsamiane ze zmianą metodologii badawczej5.

Z Zachodu też nadeszły pierwsze postsowieckie syntezy historii Ukrainy. Przetłumaczona $\mathrm{z}$ angielskiego Historia Ukrainy kanadyjskiego historyka Oresta Subtelnego stała się absolutnym bestsellerem na początku lat dziewięćdziesiątych ${ }^{6}$. Nieco inne podejście chciał zaproponować Instytut Europy Środkowej i Wschodniej w Lublinie i jego kierownik Jerzy Kłoczowski, który zapoczątkował pisanie nowych syntez historii obszaru nazywanego regionem ULB (Ukraina, Litwa, Białoruś). Autorami syntez mieli być lokalni historycy, którzy znali osiągnięcia zachodniej historiografii. W ramach tego projektu powstała i nowa historia Ukrainy. Autorką pierwszej części poświęconej średniowieczu i wczesnym czasom nowożytnym była badaczka z Kijowa Natalia Jakowenko, drugą - od czasów nowożytnych do współczesności - napisał historyk ze Lwowa Jarosław Hrycak. Te syntezy, otwarte na najnowsze trendy w zachodniej historiografii, zostały opublikowane w językach ukraińskim i polskim ${ }^{7}$,

${ }^{4}$ I. Krastev, S. Holmes, The Light that Failed. A Reckoning, London 2019.

${ }^{5}$ A. Portnov, "Zahìdni” katehoriï v ukraïns'kij postradâns'kìj istorìohrafii. Movnì zmìny $v$ epohu perekladiv, „Ukraïna Moderna” 2010, 5 (16), s. 153-182.

${ }^{6}$ O. Subtelny, Ukraine. A History, Toronto 1988. Ukraińskie tłumaczenie syntezy Subtelnego zostało opublikowane na początku lat dziewięćdziesiątych w ponad 100 tys. egzemplarzy.

7 N. Jakowenko, Historia Ukrainy. Od czasów najdawniejszych do końca XVIII wieku, Lublin 2000; J. Hrycak, Historia Ukrainy 1772-1999. Narodziny nowoczesnego narodu, Lublin 2000. 
a książka Jakowenko także po rosyjsku ${ }^{8}$. Na polskich uniwersytetach stały się podstawą do nauczania historii Ukrainy, ale przekładów na „zachodnie" języki się nie doczekały.

Po roku 2000 najbardziej popularne nowe syntezy ukraińskiej historii były wydawane najpierw po angielsku. Po pomarańczowej rewolucji Serhy Yekelchyk opublikował przegląd Ukraine. Birth of a Modern Nation ${ }^{9}$ (wydany następnie także w języku polskim ${ }^{10}$ ). Natomiast po Rewolucji Godności Serhii Plokhy wydał książkę The Gates of Europe. A History of Ukraine $^{11}$. Obydwaj autorzy to ukraińscy badacze, którzy na początku lat dziewięćdziesiątych wyjechali z Ukrainy i zrobili naukową karierę na Zachodzie: Yekelchyk w Australii i Kanadzie, Plokhy w Kanadzie i Stanach Zjednoczonych.

Wśród współczesnych syntez historii Ukrainy na oddzielną uwagę zasługuje praca kanadyjskiego historyka Paula Roberta Magocsiego, której celem jest przedstawienie polietnicznej wizji historii terenów dzisiejszej Ukrainy ${ }^{12}$. Tę książkę można rozpatrywać jako swojego rodzaju odpowiedź na postulat twórcy Harvard Ukrainian Research Institute, wybitnego turkologa Omeljana Pritsaka. Jeszcze w 1990 r. na Pierwszym Kongresie Międzynarodowego Stowarzyszenia Ukrainistów w Kijowie sformułował on założenie, że ukraińska historia ma za zadanie „badać przeszłość wszystkich historycznych wspólnot i instytucji państwowych, które znajdowały się na terytorium dzisiejszej Ukrainy, a nie ograniczać się do państwowości określanej jako «swoja, etnicznie ukraińska»"13.

Inny ważny postulat $\mathrm{z}$ początku lat dziewięćdziesiątych został sformułowany przez amerykańskiego historyka Marka von Hagena na łamach czasopisma „Slavic Review”: „Płynność granic, przenikanie się kultur, multietniczne społeczności są tym, co może uczynić ukraińską historię «nowoczesną» przestrzenią do badań [--]. Ukraińska historia może posłużyć jako wspaniałe narzędzie, żeby obalić dominację koncepcji narodowo-państwowej i pomóc zbadać najbardziej kontrowersyjne aspekty formowania się tożsamości, tworzenia kultury i kolonialnych instytucji i struktur"14.

${ }^{8}$ N. Âkovenko, Očerk istorii Ukrainy v srednie veka i rannee novoe vremâ, Moskva 2012.

9 S. Yekelchyk, Ukraine. Birth of a Modern Nation, Oxford 2007.

10 S. Yekelchyk, Ukraina. Narodziny nowoczesnego narodu, Kraków 2009.

11 S. Plokhy, The Gates of Europe. A History of Ukraine, New York 2015.

12 P.R. Magosci, A History of Ukraine. The Land and Its People, Toronto 1996, 2010. Wydanie polskie: Historia Ukrainy. Ziemia i ludzie, Kraków 2018.

13 O. Prìtsak, Ŝo take istoriâ Ukraïny?, „Slovo ì čas” 1991, 1, s. 56.

${ }^{14}$ M. von Hagen, Does Ukraine Have a History?, „Slavic Review” 54, 1995, 3, s. 670, 673. 
Jednak wymienione idee nie zdominowały (a wręcz pozostały na marginesie) rozwoju ukraińskiej historiografii epoki postsowieckiej. Większy wpływ miały realia socjalno-ekonomiczne i kulturowe. W tym zakresie widoczny był wciąż silny wpływ czasów ZSSR. Mogę wymienić chociażby utrzymanie praktycznie niezreformowanej instytucji Akademii Nauk i specjalnej państwowej struktury w postaci Komisji ds. Stopni Naukowych. Sytuacja zaczęła się trochę zmieniać dzięki naukowym projektom finansowanym przez zachodnie fundacje, które promowały określoną tematykę i priorytety metodologiczne. Nieustannie postępowała jednak fragmentacja ukraińskiej historiografii (przede wszystkim pod względem tematyczno-regionalnym, kiedy historycy z każdego regionu coraz bardziej skupiali się na tematyce lokalnej). Ciągle również słaba była mobilność wewnętrzna ukraińskich badaczy. Natomiast rosyjska aneksja Krymu i wojna na Donbasie - co całkiem zrozumiałe - jeszcze bardziej zaostrzyły polityzację historiografii i uwidoczniły partyjno-polityczne podziały.

Mimo wszystko na Ukrainie były i są publikowane dobrej jakości prace - nie tylko zresztą w takich tradycyjnych ośrodkach intelektualnych jak Kijów czy Lwów. Niestety często nie są wystarczająco omawiane nawet na Ukrainie, nie mówiąc już o możliwościach wpływu na anglo-, niemiecko- czy nawet polskojęzyczne studia ukrainistyczne.

Należy wspomnieć także o zasygnalizowanym już rozwoju możliwości kształcenia i uzyskiwania stopni naukowych za granicą. $Z$ jednej strony warto to uznać za szansę na rozwój. $Z$ drugiej strony jednak nierówności ekonomiczne, skutkujące słabym opłacaniem pracowników skłaniają do migracji wielu ambitnych badaczy z Ukrainy (niebezpieczeństwo „drenażu mózgów”) i gotowości do przyjmowania „zachodnich reguł gry”.

Polityka państwa ukraińskiego w zakresie nauki i oświaty opiera się, nieco paradoksalnie, na pewnym pojednaniu elementów systemu sowieckiego z mechanizmami zapożyczonymi z neoliberalnego modelu uniwersytetu. Według oficjalnych deklaracji ma to „zbliżać” Ukrainę do międzynarodowych standardów. Ukraińskie instytucje badawcze często zachowują się jednak jak neofici i próbują ortodoksyjnie przestrzegać zasad, w tym m.in. stawiają wyśrubowane wymagania odnośnie do „indeksu cytowań” albo liczby publikacji w recenzowanych czasopismach anglojęzycznych. Paradoksalnie np. w Niemczech obserwuje się dużo bardziej elastyczne podejście do tych wymogów. Warto zwrócić na to uwagę, gdyż na ukraińskich uniwersytetach wykładowcy funkcjonują w dużo trudniejszych warunkach niż niemieccy koledzy, jeśli chodzi o wynagrodzenie, obciążenie godzinami dydaktycznymi i wciąż ograniczony dostęp do zagranicznych publikacji. 
Rok temu profesor historii wschodniej Europy z Uniwersytetu w Bochum, Stefan Plaggenborg, porównał triumf neoliberalnego modelu uniwersytetu w Niemczech z „sowietyzacją nauk humanistycznych” 15 . Wśród jej oznak wymienił: planowe podejście do badań naukowych i nadmierne przywiązanie do znaczenia wskaźników (cytowań i tym podobnych), kluczową rolę biurokracji w wyznaczaniu kierunków rozwoju uniwersytetu, kolektywizację badań humanistycznych (zainteresowanie zespołowymi projektami i dewaluacją prac naukowych pojedynczych badaczy), a wreszcie rozkwit konformizmu.

Artykuł Plaggenborga powinien, zdawałoby się, wywołać dyskusję. Ale do niej nie doszło. Czemu? Być może niektórzy poczuli się już komfortowo na zdobytych stanowiskach. Inni, w niestającej walce o krótkoterminowe granty i kontrakty, mogli uznać za nierozsądne (a wręcz niebezpieczne) zabieranie głosu na takie „śliskie” tematy. We wspomnianym tekście Plaggenborg mówił o problemach w zakresie funkcjonowania nauk humanistycznych na współczesnym niemieckim uniwersytecie. Nie poruszył jednak kulturowej i politycznej roli historii jako nauki we współczesnym społeczeństwie. W końcu to nie przypadek, że dziś np. w Niemczech istnieje tylko jedna uniwersytecka katedra historii wojskowej (w Poczdamie), a na wszystkich poziomach życia akademickiego (od zwykłego wykładu po tematy prac magisterskich i rozpraw doktorskich) odczuwalne są skutki tego, co ostatnio nazwano „polityką tożsamości” (identity politics).

Ta tendencja z jednej strony prowadzi do podjęcia tematów związanych z grupami wcześniej zaniedbywanymi w nauce, z drugiej jednak ideologiczny ton „polityki tożsamości” doprowadził do sytuacji, w której, według słów rosyjskiego historyka literatury i profesora Uniwersytetu Oksfordzkiego Andrieja Zorina, najważniejsza staje się dziś umiejętność „właściwego obrażania/oburzania się" w imieniu którejś grupy, aby potem stawiać siebie w pozycji moralnej wyższości upoważniającej do wydawania wyroków za pogwałcenie ustalonych tabu ${ }^{16}$.

Profesor Uniwersytetu Columbia Mark Lilla, rozważając perspektywy liberalnej ideologii w Ameryce, z bólem opisał realia współczesnego amerykańskiego uniwersytetu, w którym „zwycięzcą każdego sporu będzie ten, kto potrafi przywołać moralnie wyższą tożsamość (morally superior identity)” oraz „tylko osoby z zatwierdzonym statusem tożsamości

15 S. Plaggenborg, Die strukturelle Sowjetisierung der Geisteswissenschaften, „Frankfurter Allgemeine Zeitung" 3 VII 2019, s. 4.

16 A. Zorin, My nastojčivo iŝem slučaâ byt' oskorblennymi, https://www.colta.ru/ articles/society/21234-my-nastoychivo-ischem-sluchaya-byt-oskorblennymi (dostęp: 17 V 2019). 
(approved identity status), podobnie jak szamani, mogą zabierać głos w niektórych sprawach"17. Ta obserwacja, której potwierdzenie łatwo znaleźć w przestrzeni publicznej nie tylko w Stanach Zjednoczonych, prowadzić może do postawienia wielu ważnych pytań na temat normatywnego charakteru sfery publicznej (i naukowej) w czasach tzw. postprawdy i wszelkiego rodzaju manipulacji medialnych ${ }^{18}$. Kto i dlaczego ma prawo się wypowiadać? Do czego prowadzi „selektywna wrażliwość” na pewne procesy z otaczającego nas świata? Jak w sytuacji nowych reguł zachować swobodę i wolność krytycznej refleksji i wypowiedzi, co - podkreślam wcale nie wiąże się z akceptowaniem ksenofobii czy podobnych zjawisk? Czy jest możliwe we współczesnym świecie, z jego sztywnymi podziałami moralnymi i ideologicznymi, wartościowe, uczciwe i krytyczne podejście w badaniach historycznych? Jak połączyć dążenie do maksymalnej obiektywności ze świadomością nieosiągalności ideału?

Sprawdzianem dla środowiska naukowego (i nie tylko) stała się rosyjska polityka względem Ukrainy z aneksją Krymu i otwartym wojskowym wtargnięciem do Donbasu. Dokładnie w czasie wybuchu konfliktu redaktorzy międzynarodowego czasopisma „Ab Imperio” zwrócili się z prośbą o refleksje, jak „Dyscyplina znana wcześniej jako Russian Studies przyczyniła się do przygotowania opinii publicznej i podejmowania decyzji politycznych, które umożliwiły tragiczny rozwój wydarzeń na Ukrainie i w Rosji"19. Niestety i ta prośba pozostała praktycznie bez odzewu. Natomiast inne znaczące międzynarodowe czasopismo naukowe „Kritika” opublikowało debatę o „kryzysie ukraińskim i historii”"20. Pokazała ona brak gotowości wielu historyków do refleksji nad własnymi uprzedzeniami i skłonność do powtarzania nowych schematów propagandowych. Artykułem analitycznym odpowiedział Andriy Zayarnyuk ${ }^{21}$, ale i ten tekst dyskusji nie wywołał.

17 M. Lilla, The Once and Future Liberal. After Identity Politics, New York 2017, s. 90-91.

18 P. Pomerantsev, M. Weiss, The Menace of Unreality. How the Kremlin Weaponizes Information, Culture and Money, https://imrussia.org/media/pdf/Research/Michael_Weiss_ and_Peter_Pomerantsev__The_Menace_of_Unreality.pdf (opublikowane: 11 IX 2013). Zob. także P. Pomerantsev, Nothing is True and Everything is Possible. Adventure in Modern Russia, New York 2014; idem, This is Not Propaganda. Adventures in the War Against Reality, London 2019.

19 Forum AI: Ukraine and the Crisis of „Russian Studies”: Participant Observation on History in the Making, http://net.abimperio.net/ru/node/3320 (opublikowane 23 VII 2014, strona internetowa już nie istnieje).

${ }^{20}$ Forum. Ukrainian Crisis and History, „Kritika. Explorations in Russian and Eurasian History" 16, 2015, 1, s. 121-155.

21 A. Zayarnyuk, A Revolution's History, A Historians' War, „Ab Imperio” 2015, 1, s. $449-479$. 
Banalna teza, że otwarta, rzeczowa debata jest jak powietrze dla rozwoju nauki, staje dziś pod znakiem zapytania. Optymistyczne złudzenie z początku lat dziewięćdziesiątych XX w. dotyczące braku alternatywy wobec „wolnej, zorientowanej na Zachód historiografii” wymaga przemyślenia. Od tego, czy podjęta zostanie dyskusja na ten temat, zależą szanse na utrzymanie pluralizmu środowiska naukowego i nauczania uniwersyteckiego.

\section{Streszczenie}

Autor wymienia dwa dominujące kierunki w rozwoju postsowieckiej historiografii ukraińskiej - „nacjonalizację" (w sensie „powrotu do tradycji narodowych” i „wypełnienia białych plam” w sowieckiej narracji o przeszłości) i „internacjonalizację" (w sensie zbliżenia z zachodnią humanistyką, przyjęcia jej aparatu pojęciowego i priorytetów tematycznych). Przy tym, „strategie udomowienia” koncepcji „zachodnich" sprowadzały się głównie do zmiany samego języka bez głębszej refleksji na temat kontekstu zapożyczonych kategorii. Jednocześnie, na poziomie strukturalnym, na Ukrainie utrzymały się praktycznie niezreformowane instytucje Akademii Nauk i specjalnej państwowej struktury w postaci Komisji ds. Stopni Naukowych. Autor porównuje tę sytuację z próbami krytycznej analizy obecnych tendencji w życiu uniwersyteckim Niemiec lub Stanów Zjednoczonych i stawia szereg pytań, związanych z coraz bardziej powszechną akceptacją postulatów „polityki tożsamości” oraz nowej „selektywnej wrażliwości”: jak w sytuacji nowych reguł zachować swobodę i wolność krytycznej refleksji i wypowiedzi? Czy jest możliwe we współczesnym świecie, z jego sztywnymi podziałami moralnymi i ideologicznymi, wartościowe, uczciwe i krytyczne podejście w badaniach historycznych? Jak połączyć dążenie do maksymalnej obiektywności ze świadomością nieosiągalności ideału?

\section{Some Reflections on (Not Only) Ukrainian Post-Soviet Historiography}

The author speaks about two dominant trends in the development of post-Soviet Ukrainian historiography: 'nationalisation' (understood as the 'return to national traditions' and 'filling in the blanks-the so-called 'białe plamy' (white spots) in the Soviet narrative about the past), and 'internationalisation', understood as a rapprochement with the Humanities in the West, the adoption of its conceptual apparatus and thematic priorities. The 'domestication strategies' of 'Western' concepts amounted mainly to changing the language of historical scholarship as such, without a deeper reflection upon the context of the borrowed categories. At the same time, at the structural level, the Ukrainian institutions of the Academy of Sciences 
and the special state structure in the form of the Higher Attestation Commission for academic degrees remained virtually unreformed. The author compares this situation with attempts at critical analysis of current trends in university life in Germany and the United States, and poses several questions about the increasingly widespread acceptance of the postulates of 'identity politics' and a new 'selective sensibility': How, in the face of new rules, is academic liberty and the freedom of critical reflection and expression to be preserved? Is it possible in the modern world, with its inceasingly rigid moral and ideological divisions, to maintain a valuable, honest, and critical approach to historical research? How can one combine the pursuit of maximum objectivity with the awareness of the unattainability of the ideal?

\section{Bibliografia}

Âkovenko Natalâ, Očerk istorii Ukrainy $v$ srednie veka $i$ rannee novoe vremâ, NLO, Moskva 2012.

Aron Raymond, Introduction à la philosophie de l'histoire. Essai sur les limites de l'objectivité historique, Gallimard, Paris 1986.

Forum AI: Ukraine and the Crisis of „Russian Studies”: Participant Observation on History in the Making, http://net.abimperio.net/ru/node/3320 (opublikowane: 23 VII 2014, strona internetowa już nie istnieje).

Forum. Ukrainian Crisis and History, „Kritika. Explorations in Russian and Eurasian History" 16, 2015, 1, s. 121-155.

Hagen von Mark, Does Ukraine Have a History?, „Slavic Review” 54, 1995, 3, s. 658-673. Hrycak Jarosław, Historia Ukrainy 1772-1999. Narodziny nowoczesnego narodu, Instytut Europy Środkowo-Wschodniej, Lublin 2000.

Jakowenko Natalia, Historia Ukrainy. Od czasów najdawniejszych do końca XVIII wieku, Instytut Europy Środkowo-Wschodniej, Lublin 2000.

Krastev Ivan, Holmes Stephen, The Light that Failed. A Reckoning, Allen Lane, London 2019.

Lilla Mark, The Once and Future Liberal. After Identity Politics, HarperCollins, New York 2017.

Lysâk-Rudnyc'kyj Ìvan, İstoryčnì ese, t. 1-2, Osnovy, Kyïv 1994.

Magocsi Paul R., Historia Ukrainy. Ziemia i ludzie, Księgarnia Akademicka, Kraków 2018.

Magosci Paul R., A History of Ukraine. The Land and Its People, University of Toronto Press, Toronto 1996, 2010.

Plaggenborg Stefan, Die strukturelle Sowjetisierung der Geisteswissenschaften, „Frankfurter Allgemeine Zeitung" 3 VII 2019, s. 4.

Plokhy Serhii, The Gates of Europe. A History of Ukraine, Basic Books, New York 2015. Pomerantsev Peter, Nothing is True and Everything is Possible. Adventure in Modern Russia, Public Affairs, New York 2014.

Pomerantsev Peter, This is Not Propaganda. Adventures in the War Against Reality, Faber and Faber Ltd., London 2019. 
Pomerantsev Peter, Weiss Michael, The Menace of Unreality: How the Kremlin Weaponizes Information, Culture and Money, https://imrussia.org/media/pdf/ Research/Michael_Weiss_and_Peter_Pomerantsev_The_Menace_of_Unreality. pdf (opublikowane: 11 IX 2013).

Portnov Andrìi, „Zahidni” katehorï v ukraïns'kij postradâns'kì ìstorìohrafii. Movnì zmìny v epohu perekladiv, „Ukraïna Moderna” 2010, 5 (16), s. 153-182.

Prìtsak Omeljan, Ŝo take istoriâ Ukraïny?, „Slovo ì čas” 1991, 1, s. 53-60.

Subtelny Orest, Ukraine. A History, University of Toronto Press, Toronto 1988.

Yekelchyk Serhy, Ukraina. Narodziny nowoczesnego narodu, Wydawnictwo UJ, Kraków 2009.

Yekelchyk Serhy, Ukraine. Birth of a Modern Nation, Oxford University Press, Oxford 2007.

Zayarnyuk Andriy, A Revolution's History, A Historians' War, „Ab Imperio” 2015, 1, s. 449-479.

Zorin Andrej, My nastojčivo iŝem slučaâ byt' oskorblennymi, https://www.colta.ru/ articles/society/21234-my-nastoychivo-ischem-sluchaya-byt-oskorblennymi (dostęp: 17 V 2019).

Biogram: prof. dr Andrij Portnow, profesor historii Ukrainy na Uniwersytecie Europejskim Viadrina (Frankfurt nad Odrą), dyrektor Prisma Ukraïna Research Network Eastern Europe w Berlinie. Zainteresowania badawcze: historia intelektualna oraz historiografia Polski, Rosji i Ukrainy, urbanistyka historyczna, genocide studies; kontakt: portnov@europa-uni.de.

Author: prof. dr. Andrii Portnov, professor of Ukrainian history at the European University Viadrina (Frankfurt an der Oder), director of the Prisma Ukraïna Research Network Eastern Europe in Berlin. His scholarly interests include: intellectual history and historiography of Poland, Russia, and Ukraine, historical urban planning, genocide studies; contact: portnov@europa-uni.de. 